\title{
Efficacy of different solvent extracts from the aerial parts of Costus speciosus (Koen.) for the potential antibacterial activity against selected human pathogenic bacteria
}

\author{
C Mahendranathan ${ }^{\mathrm{a} *}$ and AHYG Abhayarathne ${ }^{\mathrm{b}}$ \\ a*chandrakantha@esn.ac.lk \\ a \& b Department of Botany, Eastern University, Vantharumoolai, Sri Lanka
}

\begin{abstract}
Costus speciosus (Koen ex.Retz.) is an ornamental plant and has also been used in traditional medicinal systems, mainly in India and Sri Lanka. This research article reveals the antibacterial activity of the leaves of Costus speciosus (Koen.) and its efficacy in different solvents, acetone, ethanol and sterilized distilled water (aqueous), against selected human pathogenic bacteria, Escherichia coli (E. coli) and Staphylococcus aureus (S. aureus). The leaves were tested for antibacterial activity, using agar well diffusion method at the test concentrations of 25, 50 and $75 \mathrm{mg} / 100 \mu \mathrm{l}$ of these solvents, separately. The maximum inhibitory action was observed in ethanol extracts against both bacterial strains at $75 \mathrm{mg} / 100 \mu \mathrm{l}$ concentration. The Minimum Inhibitory Concentration (MIC) for Acetone and ethanol extracts of Costus speciosus were $12.5 \mathrm{mg} / 100 \mu \mathrm{l}$ and $6.25 \mathrm{mg} / 100 \mu \mathrm{l}$ respectively against E. coli whereas it was $12.5 \mathrm{mg} / 100 \mu \mathrm{l}$ against S. aureus for both extracts. The aqueous, ethanol and acetone extracts showed concentration-dependent antibacterial activity against the tested bacteria with the zone of inhibition. Among the solvents used, the acetone showed higher inhibitory activity yet clear and significant inhibition zones were also observed from the aqueous and ethanol leaf extracts. Thereby, the results revealed the medicinal potential of the leaf extracts of Costus speciosus (Koen.) against various infectious diseases to develop a drug with appropriate solvents.
\end{abstract}

Key words: Escherichia coli, Staphylococcus aureus, antibacterial activity, solvent 


\section{Introduction}

Infectious diseases are the major world's leading cause of premature deaths and killing almost 50000 people every day [1]. However, currently, the major concern in human health is the less effectiveness of commercial antibiotics against several human pathogenic bacterial isolates. Specially, Staphylococcus aureus, a gram-positive bacterium from Staphylococcaceae family, and this pathogenic bacteria has been as one of the world's most important infectious agents that causes disease outbreaks, related to food consumption and hospital-associated infections etc. $[2,3]$.

Plants, on the other hand, are playing a significant role in maintaining human health and improving the wealth of human life [4] and plants have also been used for centuries to treat infectious diseases and are considered as an important source of new antimicrobial agents [5].

The traditional medicine has been greatly accepted as an alternative form of health care and the development of microbial resistance to the available antibiotics. Thereby, there has been renewed interest in natural medicines, obtained from various plant extracts.

The resistance of pathogenic bacterial strains to antibiotics is the major burning issue around the world. Pharmacological industries have produced various new antibiotics ever since, but microorganisms have slowly developed resistance to these drugs because bacteria have the genetic capability to transmit and acquire resistance to these drug [6]. In addition to these problems, antibiotics are sometimes associated with adverse effects on host organism which include immunosuppressant, hypersensitivity and allergic reactions [7]. This has created immense clinical problems in the treatment of infectious diseases. Plants and plant products are a better alternative compared to antibiotics and other synthetic drugs which display negative side effects such as sensitization reactions, and disruption of the metabolic processes in the body via interaction with the body system [8]. Hence in this study the leaf extracts of Costus speciosus, which were sampled from Gampaha district, Western province of Sri Lanka, were screened to evaluate the in -vitro antibacterial activity against human pathogenic bacteria since the past research works have mostly focused on the medicinal properties of the rhizome of this plant. In addition, the efficacy of the leaf extracts from the solvents, acetone, ethanol and distilled water was also compared in this study in order to obtain a better result for the antibacterial activity of the leaves of this medicinal plant.

\section{Materials and methods}

\subsection{Collection of Plant materials}

The fresh and healthy leaves, without any disorders, of Costus speciosus (Local name: Thebu, Tamil name: Kottam/Kudavam) were collected from Gampaha district, Western province, Sri Lanka, during the period of September-October 2019. The plant specimens were verified with the Herbarium, department of Botany, Eastern University, Vantharumoolai, Sri Lanka.

\subsection{Preparation of leaf extracts}




\subsubsection{Ethanol and Acetone extractions}

The leaf samples were shade-dried until obtained a constant weight and pulverized to produce fine powder by using electric grinding machine. The resulted powders were extracted by using three different solvents as acetone, ethanol and water.

Dried powder of sample (10 g) was extracted in triplicate with $100 \mathrm{ml}$ of ethanol and acetone, separately. The contents were kept on mechanical orbital shaker for three days (72 hours) at room temperature. The extracts were then filtered and concentrated, separately, by evaporation at $40^{\circ} \mathrm{C}[9,10]$.

\subsubsection{Aqueous Extraction}

Dried powder of each sample $(10 \mathrm{~g})$ was extracted in triplicate with $100 \mathrm{ml}$ of distilled water and was filtered after shaken continuously for three days. Filtrate was concentrated and dried in a water bath at a temperature of $100^{\circ} \mathrm{C}$. The resulted extract was stored in the refrigerator at $4^{0} \mathrm{C}$ for further studies [11].

\subsection{In vitro antibacterial activity}

In vitro antibacterial activities of different plant extracts were tested against clinically important microbial pathogens of Escherichia coli, Staphylococcus aureus, obtained from Microbiology lab, Department of Pathophysiology, Faculty of Healthcare Sciences, Eastern University, Batticaloa, Sri Lanka and were maintained on nutrient agar slants. Agar well diffusion method was used to evaluate the antibacterial activities of ethanol, acetone and aqueous crude extracts of plant leaves. Bacteria cell suspensions were adjusted to turbidity standards to prepare $1 \times 10^{8}$ bacteria cells $/ \mathrm{ml}$ inoculum from serial dilution by using hemocytometer. Then $0.1 \mathrm{ml}$ of each bacterial suspension was inoculated on the sterilized nutrient agar medium in petri dishes through spread plate technique. After solidification completed, Wells of $8 \mathrm{~mm}$ in diameter and about $2 \mathrm{~cm}$ apart were made in the culture media by using sterile cork borer to make four uniform wells in each petri dish to which $100 \mu$ l of solvent extracts were added. A drop of molten nutrient agar was used to seal the base of each well. For each treatment level six replicates were maintained. Amoxicillin $(25 \mu \mathrm{g} / 100 \mu \mathrm{l})$ was used as positive control and $100 \mu \mathrm{l}$ of acetone, ethanol and water were used as negative control respectively. Antibacterial activity of plant extract against bacterial strains by well diffusion technique was identified after incubation for $24 \mathrm{~h}$. at $37^{\circ} \mathrm{C}$ in the incubator and the results were obtained by measuring the zone of inhibition of growth around the well [12]. All these experiments were carried out at the Department of Botany, Eastern University, Sri Lanka.

\subsection{Determination of a Minimum Inhibitory Concentrations (MIC values)}

MIC is defined as the lowest concentration of the antibacterial agent that inhibits the microbial growth after 24hrs of incubation. Different concentrations of the plant extracts $(3.125,6.25$ and $12.5 \mathrm{mg} / 100 \mu \mathrm{l}$ ) were prepared separately by serial dilutions of the original extracts using the same solvents and MIC was determined by well diffusion method [13]. 


\subsection{Statistical analysis}

Results obtained in this study were expressed as mean inhibition zone diameter $(\mathrm{mm}) \pm$ S.D of six replicates. The data were analyzed by one way analysis of variance (ANOVA, P value < 0.05) using statistical software, MINITAB 14 system.

\section{Results and discussion}

\subsection{Antibacterial activity evaluation}

The antibacterial activity of all three solvent extracts of Costus speciosus showed concentrationdependent inhibitory activity against both bacterial strains with varying degrees of potency. The results showed that the gradual suppression of growth of S. aureus and E.coli which was exhibited by increasing concentration of ethanol and acetone extracts. Further, it was also observed that both the acetone and ethanol extracts showed significant antibacterial activity against S. aureus and E.coli where the inhibition of growth was observed at the lowest concentration of these two solvents, $25 \mathrm{mg} / 100 \mu 1$. Interestingly, the aqueous extract also showed the moderate antibacterial activity against $\mathrm{S}$. aureus and E.coli (Table I) and no inhibition zones were observed at the lowest concentration used $(25 \mathrm{mg} / 100 \mu \mathrm{l})$. Further, as per the results, E. coli was effectively inhibited by acetone extracts $(12.5 \pm 0.1 \mathrm{~mm})$ at the concentration of $25 \mathrm{mg} / 100 \mu \mathrm{l}$ and showed the maximum inhibition effect $(19.5 \pm 0.2 \mathrm{~mm})$ at the concentration of $75 \mathrm{mg} / 100 \mu \mathrm{l}$ than the other two solvents. Meanwhile, ethanol extract of Costus speciosus showed maximum inhibitory action $(18.2 \pm 0.3 \mathrm{~mm})$ on $\mathrm{S}$. aureus at $75 \mathrm{mg} / 100 \mu \mathrm{l}$. Interestingly, the inhibitory effect was also recorded at the concentrations of $50 \mathrm{mg} / 100 \mu 1$ and $75 \mathrm{mg} / 100 \mu \mathrm{l}$ of the aqueous extract as shown in Table I and the inhibition zones, by Amoxicillin, the positive control, showed the in Table II.

Table I. Mean diameter of Inhibition Zone, caused by ethanol, acetone and aqueous leaf extracts of Costus speciosus.

\begin{tabular}{ccccccc}
\hline & \multicolumn{3}{c}{ Test concentration } & \multicolumn{3}{c}{ Test concentration } \\
Solvent & \multicolumn{2}{c}{$(\mathbf{m g} / \mathbf{1 0 0 \mu l})$ against E. coli } & \multicolumn{2}{c}{$(\mathbf{m g} / \mathbf{1 0 0 \mu \boldsymbol { \mu } )}$ against S. aureus } \\
& $\mathbf{2 5}$ & $\mathbf{5 0}$ & $\mathbf{7 5}$ & $\mathbf{2 5}$ & $\mathbf{5 0}$ & $\mathbf{7 5}$ \\
\hline Ethanol & $11.5 \pm 0.2$ & $12.5 \pm 0.2$ & $18.8 \pm 0.2$ & $12.5 \pm 0.2$ & $14.8 \pm 0.2$ & $18.2 \pm 0.3$ \\
Acetone & $12.5 \pm 0.1$ & $14.2 \pm 0.1$ & $19.5 \pm 0.2$ & $10.5 \pm 0.3$ & $12.8 \pm 0.1$ & $17.6 \pm 0.1$ \\
Aqueous & - & $10.2 \pm 0.2$ & $11.3 \pm 0.5$ & - & $10.5 \pm 0.4$ & $11.6 \pm 0.2$
\end{tabular}

values are diameter of inhibition zone in $\mathrm{mm}($ Mean $\pm \mathrm{SD}),(-)$ indicates no activity, values are significantly $(\mathrm{P}<0.05)$ different.

Table II. Mean diameter of Inhibition Zone, caused by Amoxicillin at $25 \mu \mathrm{g} / 100 \mu 1$ (positive control)

Solvent

Amoxicillin (25 $\mu \mathrm{g} / 100 \mu \mathrm{l})$ against E. coli

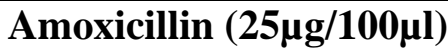
against $S$. aureus

www.ijrp.org

$\begin{array}{ccc}\text { Ethanol } & 25 \pm 0.4 & 35.5 \pm 0.1 \\ \text { Acetone } & 24.5 \pm 0.1 & 34.2 \pm 0.3 \\ \text { Aqueous } & 24.3 \pm 0.4 & 34.7 \pm 0.3\end{array}$




\subsection{Minimum Inhibitory Concentrations (MIC values) of the plant extracts}

Due to the differences in test concentrations of extracts, effectiveness of the plant extracts cannot be accurately evaluated by comparing the relative mean diameters obtained in the well diffusion method. Hence, minimum inhibitory concentration was used to determine the effectiveness of the plant extracts accurately. Acetone and ethanol extracts of Costus speciosus gave MIC values of $12.5 \mathrm{mg} / 100 \mu 1$ and $6.25 \mathrm{mg} / 100 \mu 1$ respectively against E. coli (Table III). Hence, the ethanol extracts of leaf sample exhibited strong antimicrobial activity than acetone extracts on both bacterial strains by indicating reduced MIC values.

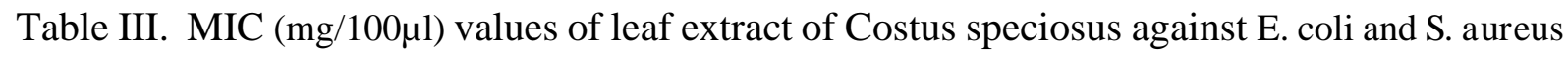

\begin{tabular}{ccc}
\hline Microorganisms & Acetone extract & Ethanol extract \\
\hline E. coli & 12.5 & 6.25 \\
S. aureus & 12.5 & 12.5 \\
\hline
\end{tabular}

Preliminary phytochemical screening was performed for the plant material and the study revealed that 12 active compounds such as alkaloids, flavonoids, tannins, terpenoids, glycosides, cardiac glycosides, saponins, quinones, anthraquinones, phenols, steroids and phlobatannin in this plant leaf extracts (Table 1V). The curative properties of medicinal plants perhaps due to the presence of various secondary metabolites and similar results have also been reported in previous studies [14]. Thus the preliminary screening tests may be useful in the detection of the bioactive principles and subsequently may lead to drug discovery and development. Most plant antimicrobial and bioactive compounds extracted during the extraction process are mainly dependent on the type of solvent. Solvents are chosen based on the yield of extracts, rate of extraction and ease of evaporation at low heat and toxicity of the solvents in bioassay [15].

Table IV. Phytochemical constituents of Costus speciosus in all three extracts, tested.

\begin{tabular}{lccc} 
Phytochemicals & Acetone & Ethanol & Aqueous \\
\hline Alkaloids & + & + & + \\
Flavonoids & + & + & + \\
Glycosides & - & - & - \\
Cardiac glycosides & - & - & - \\
Saponins & + & + & + \\
Terpenoids & + & + & + \\
Tannins & + & - & - \\
Quinones & - & + & + \\
Phenols & + & - & www.ijrp.org \\
Phlobatannin & - & + & - \\
Steroids & - & - & - \\
Anthraquinones & - & + & + \\
\hline
\end{tabular}

+) presence of phytochemicals (-) absence of phytochemicals 
compared to those extracted in water. Aqueous extracts are most commonly used primary solvent in traditional medicine because water is a universal solvent. Among the extracts investigated, ethanol extract exhibited the highest antibacterial activity followed by the acetone extracts. These observations can be due to the polarity of the compounds which were extracted by each solvent. Among the three solvents used in the study, water is the highest polar solvent and acetone is the least polar solvent. According to the results of the present study, less polar compounds exhibited more antimicrobial activity compared to high polar compounds.

It could be concluded that the findings of this study support the traditional knowledge of local users and provide a preliminary scientific validation for the use Costus speciosus leaves for antibacterial activity which will be a platform for clinical applications. Further investigation is necessary for Characterization of active components and their activity has to be evaluated in further work.

\section{Acknowledgement}

The authors are grateful to express the sincere gratitude to the Eastern University, Sri Lanka and the Academic and Nonacademic staff of the Department of Botany, Faculty of Science for their kind cooperation to make the present study, a success.

\section{References}

01. Hussain, A., Wahab, S., Zarin, I. and Hussain, M.D.S. 2010. Antibacterial activity of the leaves of Coccinia indica. Advances in Biological Research, 8: 241-248.

02. Fetsch, A., Contzen, M. and Hartelt K. 2014. Staphylococcus aureus food-poisoning outbreak associated with the consumption of ice-cream. International Journal of Food Microbiology, vol. 187, 1-6.

03. Tong, S. Y. C., Chen, L.F., and Fowler Jr.V.G. (2012). Colonization, pathogenicity, host susceptibility, and therapeutics for Staphylococcus aureus: what is the clinical relevance? Seminars in Immunopathology, vol. 34, no. 2, 185-200.

04. Muthukrishnan, S., Palanisamy, S., Santhanam, I. and Kaveriyappan, G. 2014. Phytochemical screening and antimicrobial activity of Erythrina variegata. World Journal of Pharmacy and Pharmaceutical Sciences, 3: 680-690.

05. Bereksi, M.S., Hassaïne, H., Bekhechi, C. and Abdelouahid, D.E. 2018. Evaluation of antibacterial activity of some medicinal plants extracts commonly used in Algerian Traditional Medicine against Some Pathogenic Bacteria, 10: 507-512.

06. Pradhan, B., Bhatt, D., Mishra, S. K. and Sahoo, S. 2015. Antimicrobial potential of leaves of Adhatoda vasica Nees. against human pathogens causing infections of UT, GIT and Skin. Pharmaceutical and biological evaluations, 2: 36-39.

07. Lopez, A., Hudson, J.B. and Towers, G.H.N. 2001. Journal of Ethnopharmacology, 77: 189-196.

08. Jamil, A., Shahid, M., Khan, M. M. and Ashraf, M. 2007. Screening of some medicinal plants for isolation of antifungal proteins and peptides. Pakistan Journal of Botany, 39: 211-221.

09. Jeyaseelan, E. C., Kothai, S., Kavitha, R., Tharmila, S. and Thavaranjit, A.C. 2012. Antibacterial activity of some selected algae present in the costal lines of Jaffna 
Peninsula. International Journal of Pharmaceutical and Biological Archives, 3: 352356.

10. Nasrullah, T., Suliman, M., Rahman, K., Ikram, M., Nisar, M. and Khan, I. 2012. Screening of Antibacterial activity of Medicinal plants. Journal of Applied Pharmaceutical Science, 4: 25-29.

11. Aernan, P.T., Aondofa, T.J. and Angbian, T.T. 2016. In-Vitro Antibacterial Activity of Leaf and Stem Extract of Passiflora edulis (Passion Fruit) Planted in Federal University of Agriculture Makurdi, Central Nigeria. International Journal of Science and Research, 5: 110-116.

12. Pathmanathan, M.K., Uthayarasa, K., Jeyadevan, J.P. and Jeyaseelan, E.C. 2010. Invitro antibacterial activity and phytochemical analysis of some selected medicinal plants. International Journal of Pharmacology and Biology Archives, 3: 291 - 299.

13. Mostafa, A., Al-Askar, A., Almaary, K., Dawoud, T., Sholkamy, E. and Bakri, M. 2018. Antimicrobial activity of some plant extracts against bacterial strains causing food poisoning diseases. Saudi Journal of Biological Sciences, 25: 361-366.

14. Ariharan, V.N., Meena, D.V.N., Rajakokila, M. and Nagendra, P.P. 2012. Antibacterial Activity of Costus speciosus Rhizome Extract on Some Pathogenic Bacteria. International Journal of Advanced Life Sciences, 4: 24-27.

15. Ncube, N. S., Afolayan, A. J. and Okoh, A. I. 2008. Assessment techniques of antimicrobial properties of natural compounds of plant origin: current methods and future trends. African Journal of Biotechnology, 12: 1797-1806. 